\title{
CONSIDERAÇÕES TAXONÔMICAS SOBRE O GÊNERO CUNDINAMARCA RINDGE (LEPIDOPTERA, GEOMETRIDAE) E DESCRIÇÃO DE UMA NOVA ESPÉCIE ${ }^{1}$
}

\author{
Manoel Martins Dias ${ }^{2}$
}

\begin{abstract}
TAXONOMICAL CONSIDERATIONS ON THE GENUS CUNDINAMARCA RINDGE (LEPIDOPTERA, GEOMETRIDAE) AND DESCRIPTION OF A NEW SPECIES. The genus Cundinamarca Rindge, 1983 (Geometridae, Ennominae, Nacophorini) is studied. Erilophodes indistincta Warren, 1904, Ischnopteris subalbata Dognin, 1910 and Ischnopteris nigralbata Dognin, 1913 are placed under Cundinamarca comb.n.. Two new synonyms are established: Ischnopterix subalbata whitei Prout, 1934 is a junior synonym of Ischnopteris subalbata Dognin, 1910; Cundinamarca parallela Rindge, 1983 is a junior synonym of Ischnopteris nigralbata Dognin, 1913. A new species is described: Cundinamarca rindgei. The genus is first time recorded from Brazil and Paraguay.

KEY WORDS. Lepidoptera, Geometridae, Ennominae, Nacophorini, Cundinamarca, new species
\end{abstract}

Cundinamarca Rindge, 1983 (Ennominae, Nacophorini) compreende espécies pouco representadas em coleções. Foi descrito com base em C. parallela Rindge, 1983: 196, ora considerada sinônimo júnior de Ischnopteris nigralbata Dognin,1913:32. O gênero Cundinamarca é válido e diferente de Ischnopteris Hübner, 1806 [1823] e Erilophodes Warren, 1894; algumas espécies descritas nesses dois últimos, são aqui transferidas para Cundinamarca. Face superior das asas anteriores em geral cinzenta ou olivácea, com pontos pretos difusos, dispostos irregularmente; fêmeas podem ter área preta junto à margem interna. Face superior das asas posteriores branca ou acastanhada-clara, com faixa preta, geralmente sinuosa, na margem externa; apenas em C. nigralbata (Dognin, 1913) essa faixa prolonga-se também na margem costal. Face inferior das asas branca ou acastanhada; na asa posterior, com padrão semelhante àquele da face superior. Fêmeas maiores que os machos, com antenas filiformes; bipectinadas nos machos

Pela primeira vez o gênero é registrado no Brasil e Paraguai; os exemplares de C. rindgei coletados (à luz) em São Carlos, São Paulo, Brasil, procedern de áreas de cerrado, uma delas contígua à pequena mata ciliar.

\section{MATERIAL E MÉTODOS}

O material examinado pertence às coleções entomológicas c tades a seguir, acompanhadas dos nomes de seus responsáveis e das siglas corresp undentes; estas são mencionadas na relação do material.

1) Realizado com auxilio do CNPq e FAPESP.

2) Departamento de Ecologia e Biologia Evolutiva, Universidade Federal de São Carlos. Caixa Postal 676, 13565-905 São Carlos, São Paulo, Brasil. 
Coleções examinadas: (AMNH) American Museum of Natural History, New York (F.H. Rindge), (BMNH) The Natural History Museum, London (M.J. Scoble), (UFSCAR) Departamento de Ecologia e Biologia Evolutiva, Universidade Federal de São Carlos (M.M. Dias), (USNM) National Museum of Natural History, Waşington, DC (M.A. Solis), (VOBB) Coleção Vitor O. Becker, Brasília (V.O. Becker).

\section{Cundinamarca indistincta (Warren, 1904), comb.n.}

Erilophodes indistincta Warren, 1904: 173

Ischnopteryx indistincta; Covell 1963: 842

Macho. Asa anterior, margem costal: $20 \mathrm{~mm}$. Face superior da asa anterior cinzenta-acastanhada, com pontuação difusa; linhas basal e pós-discal pouco aparentes. Face superior da asa posterior branca-acinzentada, com faixa cinzenta-acastanhada, difusa, na margem externa. Face inferior das asas branca-acinzentada, com pontuação cinzenta esparsa; parte apical da asa anterior, cinzenta-acastanhada, com mancha esbranquiçada junto à margem externa; asa posterior com faixa cinzentaacastanhada na margem externa.

Fêmea. Desconhecida.

Material examinado (1 macho). ColôMBIA, Magdalena: Santa Marta (Onaca), Engelke leg., junho-agosto, holótipo macho de Erilophodes indistincta (BMNH).

\section{Cundinamarca subalbata (Dognin, 1910), comb.n.}

Ischnopteris subalbata Dognin, 1910: 31

Ischnopterix [sic] subalbata whitei Prout, 1934: 115; syn.n.

Macho. Asa anterior, margem costal: 19-21 mm. Face superior da asa anterior cinzenta-olivácea, com pontuação cinzenta-escura disposta em manchas e traços difusos; pode haver manchas esbranquiçadas no terço apical da asa; linhas basal e pós-discal evidentes ou não. Face superior da asa posterior branca-acastanhada ou cinzenta-acastanhada; margem externa com faixa cinzenta-escura ondulada, nítida ou difusa; linha pós-discal, transversal, ondulada, evidente ou não. Face inferior das asas branca-acinzentada, com pontuação cinzenta esparsa; asa anterior com faixa cinzenta difusa e transversal passando pela célula discal, ou no ápice desta; asa posterior com faixa cinzenta-escura ondulada, na margem externa.

Fêmea. Asa anterior, margem costal: $25 \mathrm{~mm}$. Semelhante ao macho. Face superior da asa anterior com linhas basal e pós-discal evidentes; entre estas, manchas escuras junto à margem interna. Face inferior das asas com pontuação e faixas cinzentas mais evidentes.

Material examinado ( 7 machos e 1 fêmea). GuIANA FranCESA, Cayenne: Saint-Laurent-du-Maroni, diapositivo do holótipo macho de Ischnopteris subalbata (USNM).BELIZE, La Cambre, J. Lienhart leg., 30-I-1922, holótipo macho; 28-I1922, 30-I-1922, 2 parátipos machos; 22-II-1922, parátipo fềmea. Punta Gorda, J.J. White leg., V-1933, parátipo macho (holótipo e parátipos de Ischnopterix [sic] subalbata whitei) (BMNH). Punta Gorda, J.J. White leg., VIII-1934, 1 macho (BMNH). Rio Temas, J.J. White leg., 1 macho (BMNH). BRASIL, Rondônia: Porto Velho, 180m, V.O. Becker leg., no. 62815, 24-30-IV-1989, 1 macho (VOBB). 


\section{Cundinamarca nigralbata (Dognin, 1913), comb.n.}

Ischnopteris nigralbata Dognin, 1913: 32

Ischnopterynx nigralbata; Covell, 1963: 842

Cundinamarca parallela Rindge, 1983: 196; syn.n.

Macho. Asa anterior, margem costal: 19-21 mm. Face superior da asa anterior cinzenta, com pontuação difusa cinzenta-escura; linhas basal e pós-discal evidentes. Face superior da asa posterior branca; faixa larga cinzenta-escura nas margens externa e costal. Face inferior das asas branca; asa anterior com parte apical cinzenta-escura, coloração esta prolongada de forma difusa na margem costal, célula discal e em faixa transversal mediana; asa posterior com pequena mancha branca na faixa cinzenta-escura da margem externa.

Fêmea. Asa anterior, margem costal: $23 \mathrm{~mm}$. Semelhante ao macho. Face superior da asa anterior com linhas basal e pós-discal evidentes ou faixa basal preta, confluente com área da mesma cor junto à margem interna. Face inferior das asas com áreas cinzento-escuras, mais amplas.

Material examinado (5 machos e 2 fêmeas). ColôMBiA, Medina (500 m), Fassl leg., diapositivo do holótipo fêmea de Ischnopteris nigralbata (USNM). Rio Negro (800 m), Fassl leg., 1 macho (BMNH). Cundinamarca: Finca San Pablo (3 $\mathrm{Km}$ ao norte de Alban, $1800 \mathrm{~m}$ ), P. \& B. Wygodzinsky leg., 1-12-VIII-1967, 4 parátipos machos de Cundinamarca parallela (AMNH). EQUADOR, Zamora-Chinchipe, 1 fêmea (AMNH).

\section{Cundinamarca rindgei sp.n.}

Figs $1-19$

Macho. Asa anterior, margem costal: 18-21 mm. Olhos grandes e salientes; fronte saliente (Fig. 10), arredondada em vista anterior, com escamas esbranquiçadas e oliváceas, entremeadas com grupos dispersos de escamas pretas; vértice verde-oliváceo em sua maior área, com escamas brancas laterais e posteriores, e escamas pretas dispersas. Palpos labiais com três segmentos, medindo respectivamente, da base para o ápice do palpo, 0,9,0,7 e 0,2 mm; recobertos por escamas esbranquiçadas e verde-oliváceas, longas na parte inferior do segmento basal; escamas castanhas e pretas,em grupos, no segmento mediano. Antenas longas, com cerca de 90 a 100 segmentos; segmentos basais e aqueles do terço apical, simples; demais segmentos, bipectinados (Fig. 7); processos laterais mais longos aproximadamente no meio da antena, castanhos, curvos e ligeiramente dilatados no ápice; segmentos da antena com escamas dispostas em faixas transversais oliváceo-claras ou pretas, dando aspecto bandeado, irregular; terço apical oliváceo-claro.

Patágia e tégula com escamas longas, oliváceas, entremeadas com algumas esbranquiçadas; tégula com faixa oblíqua preta e escamas setiformes castanhas, apicais. Asa anterior com aréola longa e estreita e veia Sc não anastomosada com $\mathrm{R} 1$; asa posterior com veia $\mathrm{M} 2$ ausente, marcada apenas por pequeno traço, pouco aparente, no ápice da célula discal (Figs 8, 9). Área posterior do mesonoto com tufo saliente de escamas, seguido de outros dois, um pouco maiores que o precedente, 

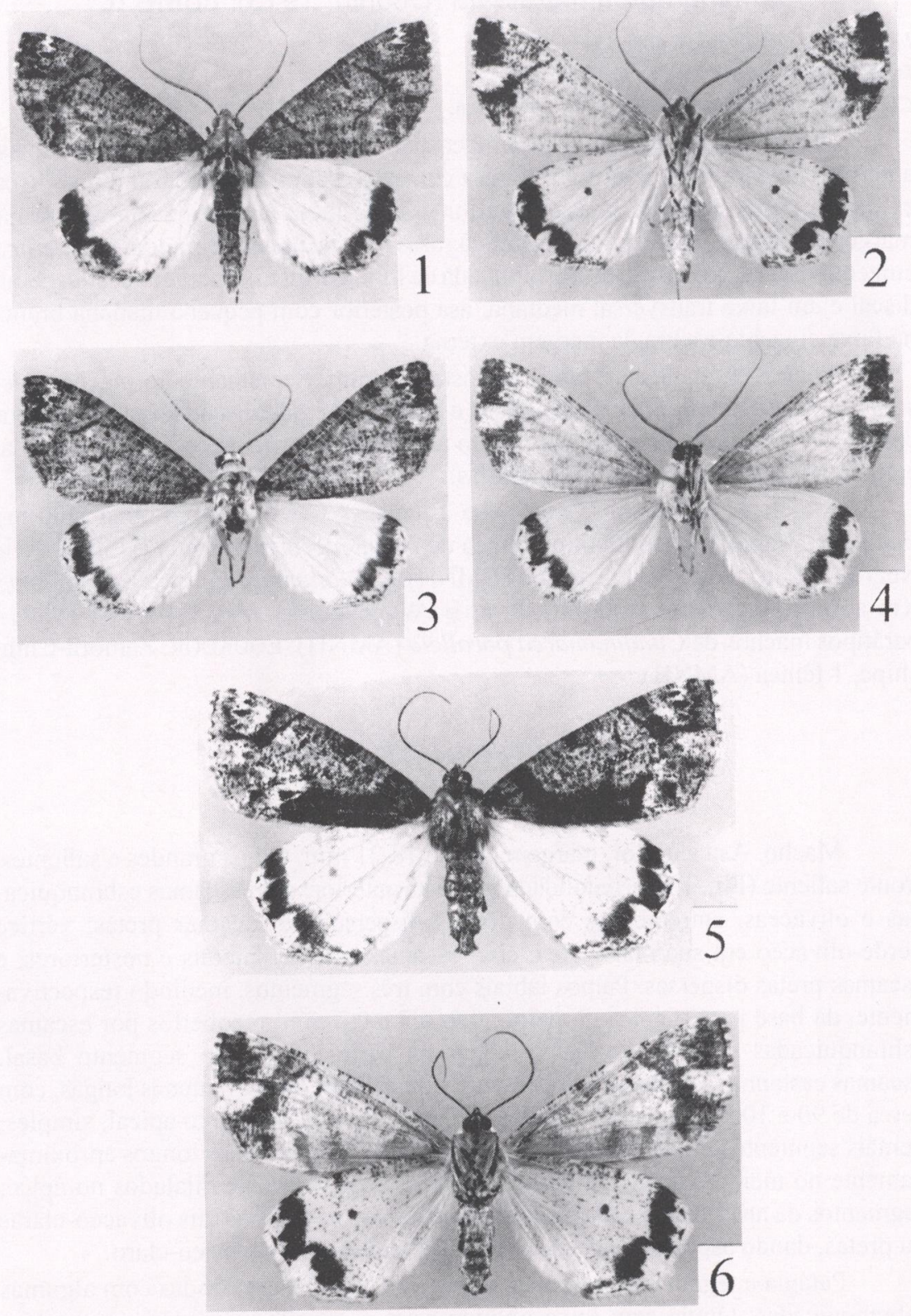

Figs 1-6. Cundinamarca rindgei, São Carlos, São Paulo. (1) Holótipo macho; (2) idem, face inferior; (3) parátipo macho; (4) idem, face inferior; (5) parátipo fêmea; (6) idem, face inferior. 


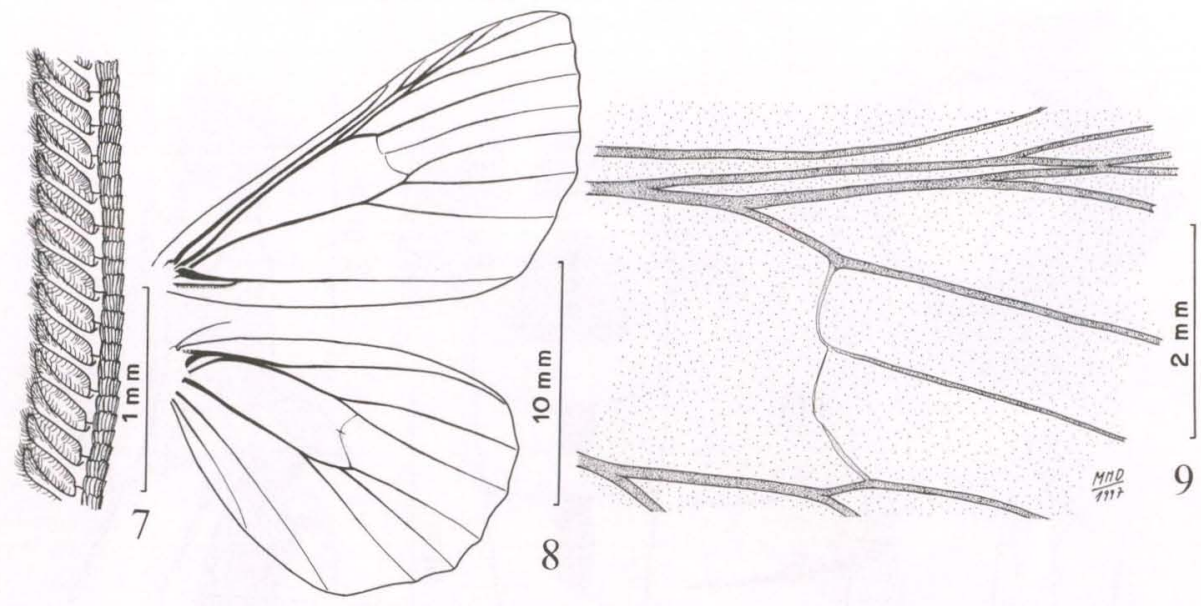

Figs 7-9. Cundinamarca rindgei, macho, São Carlos, São Paulo. (7) Antena, seção mediana, apenas uma fileira de processos laterais representada; (8) venação; (9) venação, asa anterior, aréola e ápice da célula discal.

dispostos lado a lado; metanoto com banda transversal de escamas salientes; todos com escamas na maioria pretas, entremeadas com algumas oliváceas. Área ventral e lateral do tórax, branca, acastanhada-clara anteriormente. Pernas anteriores e medianas com faixas transversais brancas, oliváceas e pretas, nas tíbias e tarsos. Pernas posteriores sobretudo brancas; tíbia dilatada, oblonga (Fig. 13), com escamas oliváceas e pretas dispersas; tarsos com manchas pretas.

Abdome com área dorsal olivácea, com escamas pretas em grupos dispersos e algumas escamas brancas; tufos salientes de escamas (oliváceas com ápice preto) sobre os segmentos 2 a 5; tufo maior no segmento 3 e muito reduzido e não saliente no segmento 6 (Fig. 11). Área ventral branca, com escamas oliváceas e pretas, dispersas.

Face superior da asa anterior cinzenta-olivácea, com pontuação cinzenta-escura disposta em manchas e traços difusos; pode haver manchas esbranquiçadas dispersas; manchas cinzento-escuras podem ser bastante acentuadas. Ponto preto no ápice da célula discal. Linha basal preta, da margem costal à margem interna; geralmente forma pequena projeção para fora entre $\mathrm{CuA} 2$ e $2 \mathrm{~A}$. Linha semelhante pós-discal, inicialmente paralela à primeira e depois curvada em ângulo abrupto ao nível de M3, dirigindo-se para dentro até atingir a margem interna. Essas linhas podem ser pouco ou apenas parcialmente aparentes.

Face superior da asa posterior sobretudo branca, com ponto cinzento, pouco aparente, no ápice da célula discal; externamente a esta pode haver linha transversal pouco marcada e descontínua, cinzenta-escura, ondulada. Margem externa da asa posterior com faixa cinzenta-escura, ondulada e variável em forma, podendo ser parcialmente ocupada por áreas claras, levemente róseas, externas.

Face inferior das asas, branca com pontuação e manchas cinzento-escuras: pontuação sobretudo no ápice e margem costal da asa anterior; pode haver pontuação 

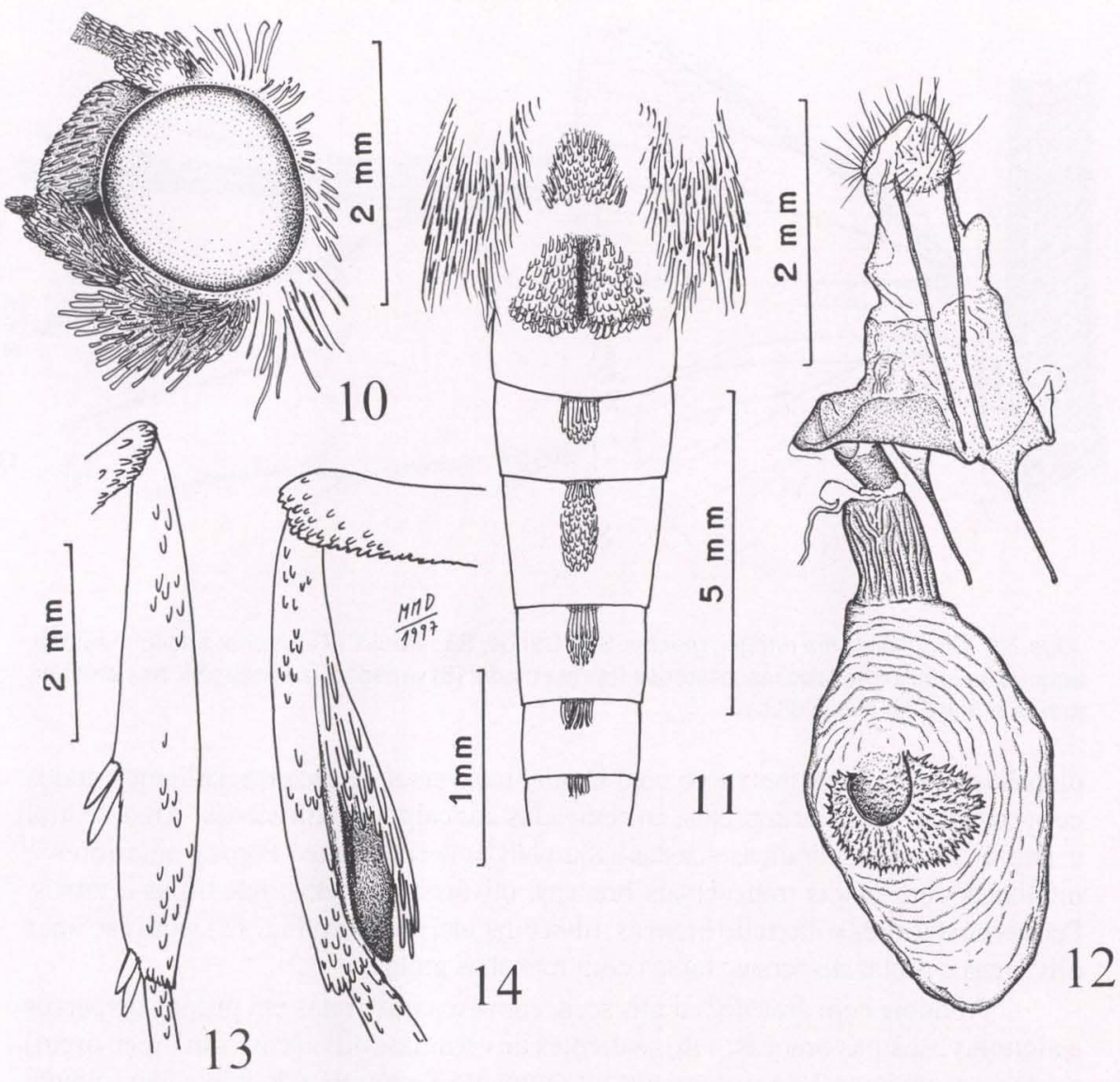

Figs 10-14. Cundinamarca rindgei, São Carlos, São Paulo. (10) Cabeça, macho, vista lateral; (11) tórax e parte do abdome, macho, vista dorsal; (12) genitália feminina, parátipo, vista látero-ventral; (13) tíbia posterior, macho; (14) tíbia anterior e epífise, macho.

na margem costal e torno da asa posterior; asa anterior com mancha no ápice e na margem externa, nesta última, contínua com a parte superior reta da linha pós-discal; na asa posterior, faixa cinzenta-escura, marginal, semelhante àquela da face superior, mas com áreas brancas externas. Ponto cinzento-escuro no ápice da célula discal de ambas as asas; pode ser reduzido na asa anterior.

Genitália masculina (Figs 15-19). Difere daquela de $C$. nigralbata $(=C$. parallela) ilustrada em Rindge, 1983:193, por: unco mais largo na base e após, abruptamente afilado; sócios mais salientes; gnato mais largo, com processos ligeiramente curvos; processos do anelo proporcionalmente mais largos.

Fêmea. Asa anterior, margem costal: 21-24 mm.

Semelhante ao macho. Olhos menores e menos salientes. Antenas com segmentos simples. Pernas posteriores com tíbias não dilatadas; estas, manchadas irregularmente de oliváceo e branco, com escamas pretas dispersas. 


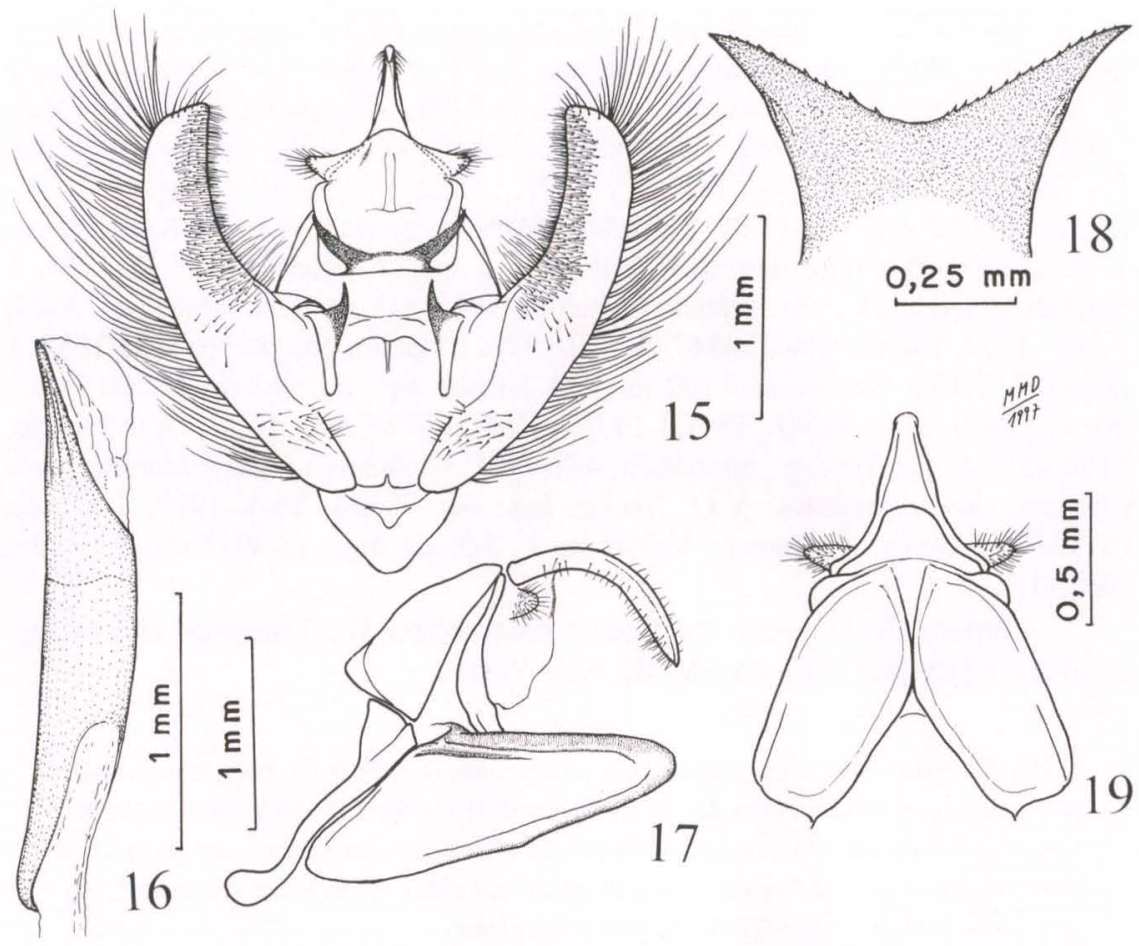

Figs 15-19. Genitália masculina. Cundinamarca rindgei, São Carlos, São Paulo, parátipo. (15) Vista ventral, edeago removido; (17) vista lateral, idem; (16) edeago, vista lateral; (18) processo do gnato, vista posterior; (19) tegume, unco e sócios, vista dorsal.

Asas anteriores mais alongadas. Face superior da asa anterior cinzenta-olivácea ou cinzenta-acastanhada. Faixa basal preta, pouco ondulada, da margem costal à margem interna; pode ser confluente com coloração preta na base da asa. Linha preta pós-discal aparente em sua porção paralela à faixa basal e alargada em faixa preta junto à margem interna; pode haver área preta evidente entre as faixas basal e pós-discal, abaixo da célula discal.

Face inferior das asas mais pontuada que aquela do macho; manchas cinzentas podem ser mais amplas na asa anterior.

Genitália feminina (Fig. 12). Papilas anais afiladas no ápice. Esterigma com lamela antevaginal esclerosada, transversal, alargada dos lados; lamela pós-vaginal aproximadamente trapezoidal, esclerosada e deprimida dos lados e membranosa no centro. Duto da bolsa com parte junto ao óstio, curta, bastante esclerosada, seguida de outra com maior diâmetro, menos esclerosada e com estrias longitudinais salientes,um pouco irregulares; entre essas partes insere-se o duto seminal. Corpo da bolsa oblongo, afilado no ápice; signo amplo, arredondado, com projeções espinescentes formando estrias aproximadamente radiais e margens com espinhos irregulares. 
Material examinado (13 machos e 3 fềmeas); excluindo o holótipo, os demais exemplares citados são parátipos. BRASIL, São Paulo: São Carlos (Universidade Federal, 850 m), M.M. Dias leg., no. 745, 28-VIII-1987, holótipo macho (UFSCAR); no. 746, 11-VI-1982, 1 macho; no. 747, 29-VIII-1986, 1 macho; no. 748, 22-XII-1986, 1 macho; no. 749, 24-IV-1991, 1 fêmea (UFSCAR); Paraná: Rolândia, A. Maller leg., III-1948, 1 macho (AMNH); Santa Catarina: Seara (Nova Teutônia), F. Plaumann leg. 20-22-III-1953, 1 macho (AMNH); 27-XI-1953, 1 macho (AMNH); Distrito Federal: Planaltina, 1000 m, V.O. Becker leg., no. 22328, 1-XII- 1977, 1 macho; no. 34847, 5-VIII-1978, 1 macho; no. 58946, 5-XI-1988, 1 fêmea (VOBB); Planaltina, 1100 m, V.O. Becker leg., no. 96836, 16-X-1990, 1 macho; 1000 m, no. 18548, 15-XII-1976, 1 fêmea (UFSCAR); Goiás: Alto Paraíso, 1100 m, V.O. Becker leg., no. 64628, 4-X-1985, 1 macho (VOBB); Mato Grosso: Chapada dos Guimarães, V.O. Becker leg., no. 75344, 25-V-1989, 1 macho (VOBB). PARAguaI, Guaira: Villarrica, F. Schade leg., 15-VI-1924, 1 macho (BMNH).

Etimologia. O nome da espécie homenageia Dr. Frederick H. Rindge, eminente lepidopterólogo do AMNH, New York.

AGRADECIMENTOS. Aos pesquisadores mencionados na relação das coleções estudadas, pelo acesso ao material examinado. Ao Dr. Frederick H. Rindge e Dr. Malcolm J. Scoble por sugestões.À Dra Maria Alma Solis e Dra Linda M. Pitkin, pela obtenção de diapositivos respectivamente dos holótipos de I. nigralbata e I. subalbata. À Dra Núria Lopez Mercader, pelo envio de cópia da descrição original de $I$. subalbata.

\section{REFERÊNCIAS}

Covell JR., C.V. 1963. A revision of the neotropical genus Erilophodes (Lepidoptera: Geometridae). Ann. ent. Soc. Amer. 56 (6): 835-844.

Dognin, P. 1910. Hétérocères nouveaux de l'Amerique du Sud. Rennes, Fasc. 1, p.1-46.

22: $1-54$.

Prout, L.B. 1934. New species and subspecies of Geometridae. Novit. zool. 39 (2): 99-136.

RINDGE, F.H. 1983. A generic revision of the new world Nacophorini (Lepidoptera: Geometridae). Bull. Amer. Mus. nat. Hist. 175 (2): 147-262.

WARREN, W. 1904. New American Thyrididae, Uraniidae and Geometridae. Novit. zool. 11 (1): 1-173.

Recebido em 01.VIII.1997 aceito em 03.XI.1998. 